\title{
Clinical evaluation of different treatment methods for OSMF: A five-year experience with 144 cases
}

\author{
Shweta Bhatnagar \\ Associate Professor, Dept. of Dentistry, Bundelkhand Medical College, Sagar Madhya Pradesh
}

Corresponding Author:

Email: shwetakeshav@gmail.com

\begin{abstract}
Introduction: Oral submucous fibrosis (OSMF) is chronic, insidious, debilitating condition of oral cavity and sometimes pharynx, characterized by progressive hyalinization of juxtaepithelial tissue and progressive fibrosis of the oral cavity. It is a premalignant disease. The repeated ulceration in mouth and the progressive reduction of mouth opening is very debilitating to the patient. The disease once occurs does not reverse. None of the modalities provide the complete remission of the disease and are aimed at improving the functions of the mouth like chewing and opening of mouth.

Aims and Objectives: The aim of this study is to establish a treatment protocol for OSMF depending on the stage of the disease. As the disease has multiple stages, a single treatment modality is not adequate for the treatment. The treatment has to be devised according to the symptoms of the patient and the stage of the disease.

Materials and Methods: It is a retrospective study done on 144 patients who are followed up for six months. The treatment was done depending on the stage of disease and the outcomes were evaluated.

Results: The cessation of the arecanut chewing habits and regular physiotherapy is a single most important factor for the success of treatment. Noninvasive treatment methods give good results with patient in stage I and Stage II disease. In our institute, single stage pedicled nasolabial flap worked well for the patients in stage III and Stage IV disease. The good mouth opening was achieved even in patients with mouth opening less than $5 \mathrm{~mm}$.

Conclusion: The proposed protocol is very effective in treating patients with OSMF. The medicinal treatment is effective in patients with mouth opening more than $20 \mathrm{~mm}$. It helps in the resolution of symptoms and improvement of mouth opening. However, in severe cases with mouth opening less then $20 \mathrm{~mm}$, surgical treatment is required. Among the surgical treatments used by us single stage pedicled nasolabial flap gave the best results.
\end{abstract}

Keywords: Treatment protocol, Arecanut, Fibrosis.

\section{Introduction}

Oral submucous fibrosis (OSMF) is chronic, insidious, debilitating condition of oral cavity and sometimes pharynx, characterized by progressive hyalinization of juxtaepithelial tissue and progressive fibrosis of the oral cavity. This precancerous condition is caused by betelnut chewing and is mainly endemic to the Asian subcontinent. ${ }^{1,2}$ Arecanut is identified as group one carcinogen by International Agency for research on cancer (IARC)..$^{3-5}$ OSMF has a high malignant transformation rate of $7-30 \% \cdot{ }^{1-5} \mathrm{~A}$ variety of treatment modalities are suggested. ${ }^{4-6}$ The characteristic features of OSMF are loss of pigmentation, blanching and leathery texture of oral mucosa, depapillation and reduced movement of tongue, progressive reduction of mouth opening and sunken cheeks. ${ }^{7}$ The suggested pathogenesis is the arecoline and flavonoid, components of areca nut when exposed to buccal mucosal fibroblast results in the accumulation of collagen. Reduced collagenase activity and increased cross-linking of the fibers results in decreased degradation of collagen. This evidence implies that OSF may be considered a collagenmetabolic disorder resulting from exposure to areca nut. OSMF occurs at any age but is most commonly seen in adolescents and adults especially between 16 and 35 years. ${ }^{8}$ The prevalence rate in India is about 0.2 $0.5 \%{ }^{9}$ with prevalence by gender varying from 0.2 to
$2.3 \%$ in males and 1.2 to $4.57 \%$ in females. ${ }^{10}$ None of the modalities provide the complete remission of the disease and are aimed at improving the functions of the mouth like chewing and opening of mouth.

\section{Aims and Objectives}

The aim of this study is to establish a treatment protocol for OSMF depending on the stage of the disease. As the disease has multiple stages, a single treatment modality is not adequate for the treatment. The treatment has to be devised according to the symptoms of the patient and the stage of the disease.

Our protocol to address the OSMF was as follows:

1. Stop the areca nut, betel quid and any other tobacco habits

2. Medicinal treatment with lycopene $16 \mathrm{mg}$ per day for three months for the patient with mouth opening more than $20 \mathrm{~mm}$

3. Surgical treatment for patients with mouth opening less than $20 \mathrm{~mm}$.

\section{Material and Methods}

The study was approved by institutional review board and the protocol complied with the world medical association declaration of helinski. 144 patients with OSMF were included in this study. 
The patients were divided in to five groups based on the interincisal mouth opening and clinical presentation.

Stage I: Mouth opening - 35 to $45 \mathrm{~mm}$, burning sensation in mouth

Stage II: Mouth opening - 25 to $35 \mathrm{~mm}$, mottled and marble like appearance of buccal mucosa and involvement of soft palate and faucial pillars.

Stage III: Mouth opening - 15 to $25 \mathrm{~mm}$, palpable vertical fibrous bands in buccal mucosa, soft palate, pterygomandibular raphae, lips.

Stage IVa: Mouth opening $-<15 \mathrm{~mm}$, thickend fauces, shrunken fibrous bud like uvula.

Stage IVb: Mouth opening $-<15 \mathrm{~mm}$ with premalignant changes or malignancy.

Pre-operative evaluation: Among 144 patients, 63 were in stage I, 39 were in stage II, 32 were in stage III, 8 in stage IVa and 2 in stage IVb. There were 79 females and 65 males (Table 1).

Table 1

\begin{tabular}{|c|c|l|}
\hline Stage & $\begin{array}{c}\text { No. of } \\
\text { patients }\end{array}$ & Gender distribution \\
\hline I & 63 & Male 18, Female 45 \\
\hline II & 39 & Male 23, Female16 \\
\hline III & 32 & Male 15, Female 17 \\
\hline IVa & 8 & Male 7, Female 1 \\
\hline IVb & 2 & Male 2 \\
\hline
\end{tabular}

Nonsurgical treatment was done in 112 cases. Surgical intervention was done in 32 of cases. Among 32 cases, 6 were treated with double stage nasolabial flap, 7 with buccal fat pad, 2 with tongue flap, 2 with skin grafting, 7 with lasers and 8 with single stage pedicled nasolabial flap (Table 2).

Table 2: Type of surgical intervention done

\begin{tabular}{|l|c|}
\hline Type of surgical intervention & No. of cases \\
\hline Nasolabial flap double stage & 6 \\
\hline Buccal fat pad & 7 \\
\hline Tongue flap & 2 \\
\hline Skin grafting & 2 \\
\hline Laser & 7 \\
\hline Single stage nasolabial flap & 8 \\
\hline
\end{tabular}

\section{Results}

Among the patient treated with different modalities, there was $100 \%$ recurrences in patients treated with skin graft, tongue graft and lasers, $66.66 \%$ recurrences in patient treated with double stage nasolabial flap, $42.85 \%$ recurrences in patient treated with Becca fat pad flap and $33.92 \%$ recurrences with nonsurgical intervention with lycopene. We did not have any cases of recurrences with single stage pedicled nasolabial flap. Maximum mean increase of mouth opening and maximum patient satisfaction was with single stage pedicled nasolabial flap (Table 3).

Table 3

\begin{tabular}{|c|c|c|c|c|}
\hline $\begin{array}{c}\text { Type of } \\
\text { Intervention }\end{array}$ & $\begin{array}{c}\text { No. of } \\
\text { patients }\end{array}$ & $\begin{array}{l}\text { Mean increase } \\
\text { in mouth } \\
\text { opening }\end{array}$ & $\begin{array}{c}\text { Mean resolution of } \\
\text { symtoms according to } \\
\text { visual analogue scale } \\
\text { used by patient }\end{array}$ & Recurrence \\
\hline $\begin{array}{l}\text { Non-surgical with } \\
\text { lycopene }\end{array}$ & 112 & $6 \mathrm{~mm}$ & $\begin{array}{l}\text { Mean increase of } 4 \\
\text { points as compared to } \\
\text { preoperative score }\end{array}$ & 38 patients \\
\hline $\begin{array}{lr}\text { Double } & \text { stage } \\
\text { inferiorly } & \text { based } \\
\text { nasolabial flap } & \\
\end{array}$ & 6 & $11 \mathrm{~mm}$ & $\begin{array}{l}\text { Mean increase of } 2 \\
\text { points as compared to } \\
\text { preoperative score }\end{array}$ & 4 patients \\
\hline Buccal pad flap & 7 & $10 \mathrm{~mm}$ & $\begin{array}{l}\text { Mean increase of } 1 \\
\text { points as compared to } \\
\text { preoperative score }\end{array}$ & 3 patients \\
\hline Tongue flap & 2 & $6 \mathrm{~mm}$ & Same as before & 2 patients \\
\hline Skin grafting & 2 & $7 \mathrm{~mm}$ & $\begin{array}{l}\text { Mean increase of } 1 \\
\text { points as compared to } \\
\text { preoperative score }\end{array}$ & 2 patients \\
\hline Lasers & 7 & $8 \mathrm{~mm}$ & Same as before & 7 patients \\
\hline $\begin{array}{ll}\text { Single } & \text { stage } \\
\text { nasolabial flap } & \end{array}$ & 8 & $21 \mathrm{~mm}$ & $\begin{array}{l}\text { Mean increase of } 6 \\
\text { points as compared to } \\
\text { preoperative score }\end{array}$ & None \\
\hline
\end{tabular}

\section{Discussion}

The treatment of Oral submucous fibrosis is mainly aimed at relieving the symptoms of the disease and to detect the malignant changes at the early stage.
Previously it was considered as a disease of Indian subcontinent $^{11}$ because of its high occurrence and confinement of the disease with South-East Asia. Because of the popularity and easy availability of the 
betel nut and its products the disease has broken all the borders of the region and the age of occurrence. So once known as disease of Indian subcontinent it has now spread all over the world with increasing rate of occurrence. Though by initial appearance of the sign and symptoms of the disease the condition seems to be benign, it has high malignant transformation potential. Its premalignant nature was first described by Paymaster in $1956 .{ }^{12}$ A variety of surgical and nonsurgical treatment modalities have been suggested in literature. Habit cessation is considered a single most important factor for the resolution of symptoms of OSMF. Nonsurgical methods mainly use antioxidants and are reserved for initial mild cases. Lycopene is a potent antioxidant and has been shown to have potent benefits in oral premalignant lesions where it has been shown to modulate dysplastic changes. The mean increases in mouth opening with the use of antioxidant only was around $6 \mathrm{~mm}$. Out of 112 patients treated, 38 patients had relapse of symptoms and mouth opening due to noncompliance with habit cessation and postop physiotherapy. In a study done by Abhinav Kumar. ${ }^{4}$ They found that the increase in mouth opening after using lycopene was stasitically significant and lycopene should be used as first line treatment for the patients with oral submucous fibrosis. In surgical treatments, the excision of fibrous bands with split thickness skin grafting, buccal fat pad grafting, tongue graft, nasolabial flap and free flaps have been used. The results of split thickness skin grafting have been very disappointing because of postoperative contracture of graft during healing period, in our cases too we had severe relapse with the skin grafts. In our centre we did not get good results with the buccal fat pad grafting and tongue flaps also. Though, the buccal fat pad is easily accessible, the amount of graft available is highly variable and many a times insufficient, it also undergoes atrophy. The BFP also heals by secondary epithelization which leads to relapse of the mouth opening achieved. Adeyemo et al reported that major hurdles included the rather limited reach of the flap for coverage of the anterior regions of the oral cavity, the chances of damage to the parotid papilla and duct during harvesting and secondary infection in the post-operative phases. ${ }^{13}$ The tongue is usually involved by the disease and the transfer of this tissue did not give a good postoperative mouth opening, also the second surgery added to the discomfort of the patient. Apart from the short-term morbidity of the donor site in terms of speech and mastication, post-operative fibrosis and constriction of tongue mass can have deleterious effects on the lifestyle of the patient. Kamath $\mathrm{VV}$ in their systematic review reported that the most important factor against usage of a tongue flap, or for that matter any intraoral flap, is the possibility of the donor area being afflicted with the disease process. ${ }^{14}$ Chaudhry, Z., Gupta, S.R. \& Oberoi, S.S. reported that lasers can provide an alternative and better means for surgical fibrotomy in moderate OSMF as they are minimally invasive and have the advantage of short operating time, less hemorrhage, faster healing, less morbidity, less surgical-site scarring and relapse,${ }^{15}$ in our cases we could get only around $8 \mathrm{~mm}$ of increasing mouth opening which too underwent some relapse. Before we were doing a two-stage nasolabial flap and sometimes we had failures because of strangulation of the pedicle leading to the fibrosis of flap. It was also uncomfortable for the patients to undergo two surgeries. The use of the nasolabial flap for repair of orofacial defects is well established. Apart from the easy accessibility, the availability of a healthy vascular pedicle based on the inferior nasal vessels and the possibility of using this flap to cover almost all regions in the oral cavity make it a well justified choice for the treatment of OSMF. Shah and Tauro did a clinical and histological study to determine the faith of nasolabial flap and concluded that it is areliable and versatile flap for reconstruction in cases with OSMF. ${ }^{14}$ In addition, the non-involvement of the flap in the disease condition is an advantage. ${ }^{14,16}$ The pedicled single stage nasolabial flap has minimal chances of strangulation of feeder vessel, postoperative mouth opening is maintained and comparatively more comfortable for the patient. The only complication is minimal postoperative scar which was acceptable for most of the patients.

\section{Conclusion}

The proposed protocol is very effective in treating patients with OSMF. The medicinal treatment is effective in patients with mouth opening more than 20 $\mathrm{mm}$. It helps in the resolution of symptoms and improvement of mouth opening. However, in severe cases with mouth opening less then $20 \mathrm{~mm}$, surgical treatment is required. Among the surgical treatments used by us single stage pedicled nasolabial flap gave the best results. In our series we did not use the free flaps because of the complexity of the procedure and the special equipment required which are not readily available. The cessation of arecanut chewing habit remains the mainstay of any treatment protocol and considered as a major factor leading to relapse. Patient counselling to abstain from the habit and to continue the physiotherapy is required to maintain the mouth opening achieved. The understanding of patient of progressive nature of the disease and the possible complications does motivate the patient to cooperate with the treatment.

\section{Compliance with ethical standards \\ Funding: None}

Conflict of interest: Author declares there is no conflict of interest.

Ethical approval: All procedures performed in studies involving human participants were in accordance with the ethical standards of the institutional and/or national research committee and with the 1964 Helsinki declaration and its later amendments or comparable ethical standards. 


\section{References}

1. Aziz SR "oral submucous fibrosis: case report and review of diagnosis and treatment". J Oral and Maxillofac Surg 2008; 66:2386-9.

2. Rajendran R “oral submucous fibrosis". J oral Maxillofac Pathol 2003;7:1-4.

3. J. N. Khanna, N. N.Andrade "Oral submucous fibrosis: a new concept in surgical management. Report of 100 cases.” Int. J. Oral and Maxillofac. Surg. 1995;24:433439.

4. A. Kumar, A. Bagewadi, V Keluskar, M singh "Efficacy of lycopene in the management of oral submucous fibrosis." Oral Surg Oral Med Oral Pathol Oral Radiol Endod 2007;103:207-13.

5. Angadi PV, Rao S. "Management of oral submucous fibrosis: an overview." Oral Maxillofac surg 2010; 14:133-42.

6. V.V. Kamath "Surgical intervention in oralsubmucous fibrosis: A systematic analysis of literature." J. Maxillofac.Oral Surg. (july-sept2015)14(3):521-31.

7. Lambade, P., Dolas, R.S., Dawane, P. et al. "Oral Submucous Fibrosis Scoring Index to Predict the Treatment Algorithm in Oral Submucous Fibrosis" J. Maxillofac. Oral Surg. (2016) 15:18.

8. More C, Asrani M, Patel H, Adalja C "Oral submucous fibrosis-a hospital-based retrospective study." J Pearldent 2010;1(4):25-31.

9. More CB, Gupta S, Joshi J, Varma SN "Classification system for oral submucous fibrosis.” J Indian Acad Oral Med Radiol 2012;24(1):24-9.

10. Joseph AP, Rajendran R "Submucosa precedes lamina propria in initiating fibrosis in oral submucous fibrosisevidence based on collagen histochemistry." J Oral Maxillofac Pathol 2010;1:4-12.

11. Rajendran $\mathrm{R}$ “Oral submucous fibrosis: etiology, pathogenesis, and future research.” Bull World Health Organ 1994;72(6):985-996.

12. Paymaster JC "Cancer of the buccal mucosa - a clinical study of 650 cases in Indian patients." Cancer 1956;9:431-5.

13. Adeyemo WL, Ladeinde AL, Ogunlewe MO, Bambgbose BO "The use of buccal fat pad in oral reconstruction." Niger Postgrad Med J 2004;11:207-11.

14. Kamath, V.V. "Surgical Interventions in Oral Submucous Fibrosis: A Systematic Analysis of the Literature” J. Maxillofac. Oral Surg. (2015)14:521.

15. Chaudhry, Z., Gupta, S.R. \& Oberoi, S.S. "The Efficacy of ErCr:YSGG Laser Fibrotomy in Management of Moderate Oral Submucous Fibrosis: A Preliminary Study" J. Maxillofac. Oral Surg. (2014)13:286.

16. Shah and Tauro. "Nasolabial Tissue for Oral Submucous Fibrosis." J Oral Maxillofac Surg 2015.;73:2251.e1-12. 